\title{
PERANAN REVOLUSI INDUSTRI 4.0 TERHADAP MUTU PENDIDIKAN SEKOLAH MENENGAH KEJURUAN JURUSAN AKUNTANSI
}

\author{
Tony Soebijono \\ Program Studi S1 Akuntansi Universitas Dinamika \\ Jalan Raya Kedung Baruk 98, Surabaya \\ tonys@dinamika.ac.id \\ Martinus Sony Erstiawan \\ Program Studi S1 Akuntansi Universitas Dinamika \\ Jalan Raya Kedung Baruk 98, Surabaya \\ martinus@dinamika.ac.id
}

\begin{abstract}
The Prapanca 2 Surabaya Vocational High School (SMK) majoring in accounting is one entity that is willing to compete and is skilled and professional in welcoming the Industrial Revolution 4.0. So far, the principal has prepared a strategy to improve the quality of graduates to suit the needs of the business market (Business World (DU)/Industrial World (DI)). Some of the strategies used in aligning education with the demands of the 4.0 Industrial Revolution era include improving the quality of sarpras (facilities and infrastructure) in the learning process based on industrial needs (Link and Match) during the Industrial Revolution 4.0 period, the fulfillment of DU/DI standard facilities and infrastructure and increasing teacher competence is focused on the era of the Industrial Revolution 4.0. The role of the principal has a point of view broad, open, disciplined, firm, and committed.
\end{abstract}

Kata kunci: Revolusi Industri 4.0, Sekolah Menengah Kejuruan (SMK).

\begin{abstract}
ABSTRAK
Sekolah Menengah Kejuruan (SMK) Prapanca 2, Surabaya jurusan Akuntasi adalah salah satu entitas yang bersedia untuk bersaing dan terampil serta profesional menyambut Revolusi Industri 4.0. Selama ini kepala sekolah telah menyiapkan strategi untuk meningkatkan mutu lulusan agar sesuai dengan kebutuhan pasar usaha (Dunia Usaha (DU)/Dunia Industri (DI)). Beberapa strategi yang digunakan dalam menyelaraskan pendidikan dengan tuntutan era Revolusi Industri 4.0 diantaranya meningkatkan mutu sarpras (sarana dan prasarana) dalam proses pembelajaran berdasarkan pada keperluan industri (Link and Match) pada kurun waktu (zaman) Revolusi Industri 4.0, pemenuhan sarana dan prasarana
\end{abstract}


yang berstandar DU/DI dan peningkatan kompetensi guru difokuskan pada era Revolusi Industri 4.0. Peran kepala sekolah memiliki sudut pandang yang luas, terbuka, disiplin, tegas, dan memiliki komitmen.

Keywords: Industrial Revolution 4.0, Vocational High School (SMK).

\section{PENDAHULUAN}

Era saat ini adalah era teknologi, di mana semua kegiatan atau aktivitas pada semua bidang kehidupan hampir semuanya berbasis pada teknologi, terutama teknologi informasi dan komunikasi. Implementasi teknologi informasi dan komunikasi telah memberikan berbagai kemudahan dalam kehidupan umat manusia. Teknologi informasi dan komunikasi mengalami kemajuan yang sangat pesat sejak ditemukannya internet. Dengan adanya internet, dunia menjadi seperti tidak ada batas (borderless). Batas-batas fisik yang memisahkan antara satu negara dengan negara lain menjadi hilang. Setiap orang dapat berkomunikasi dengan mudah dan dengan biaya yang murah dengan orang lain yang berada di belahan dunia lain.

Penggunaan teknologi informasi dan komunikasi melahirkan bisnis-bisnis baru berbasis online pada berbagai sektor usaha dengan nilai valuasi yang sangat besar. Kondisi tersebut juga berlaku di Indonesia, di mana bermunculan bisnisbisnis berbasis online. Dalam perkembangannya bisnis-bisnis online tersebut bisa berkembang dengan sangat pesat dan merambah ke semua bidang usaha. Pada bisnis biro perjalanan melahirkan Traveloka yang menjalankan bisnis biro perjalanan berbasis daring (online). Pada bidang perdagangan barang-barang yang bersifat umum ada Tokopedia, Bukalapak, dan Blibi.com. Kemudian bisnis transportasi menggunakan motor ataupun mobil yang berbasis online dikenal nama Gojek dan Grab. Dalam perkembangannya Gojek dan Grab juga merambah bisnis makanan, minuman, pulsa, mart, berbagai macam pembayaran, dan bisnisbisnis lainnya. Bisnis berbasis daring ini berkembang dengan sangat cepat, karena berbagai kemudahan yang dapat diberikannya kepada para pelanggannya. Bisnisbisnis berbasis tradisional yang tidak mampu menyesuaikan diri akan tumbang dengan sendirinya, karena bisnis berbasis daring ini di samping memberikan banyak kemudahan dan kenyamanan kepada para pelanggannya, juga mampu menawarkan barang dan jasa dengan harga yang lebih murah kepada para pelanggannya. Hal ini dimungkinkan karena bisnis berbasis daring ini tidak membutuhkan tempat seperti gudang, toko, serta karyawan dalam jumlah banyak untuk melakukan aktivitas usahanya.

Dengan demikian bisnis berbasis daring ini mampu untuk menawarkan harga jual yang lebih murah atas barang dan jasa yang ditawarkannya. Beberapa bisnis berbasis daring di Indonesia telah mampu menyandang status unicorm, artinya memiliki nilai valuasi mencapai US\$ 1 miliar atau lebih, antara lain Traveloka, Tokopedia, Bukalapak, dan OVO. Bahkan ada 1 bisnis berbasis daring yang telah menyadang status decacorn, artinya memiliki nilai valuasi mencapai US\$ 10 miliar atau lebih, yaitu Gojek. 
Pengaruh kemajuan teknologi informasi dan komunikasi juga berpengaruh pada dunia pendidikan. Pendidikan pada saat ini harus mengikuti era teknologi. Pada bidang pendidikan, teknologi informasi dan komunikasi berperan dalam mempermudah perolehan informasi maupun sebagai pembantu media belajar siswa. Siswa, mahasiswa, guru/dosen, dan praktisi dapat dengan mudah dalam memperoleh informasi dan melakukan komunikasi. Materi-materi pembelajaran dapat diperoleh dengan cepat, sesuai dengan apa yang dibutuhkan serta dapat melakukan kegiatan belajar kapan dan belajar di mana saja. Hal ini tentunya akan menjadikan proses belajar mengajar menjadi lebih fleksibel dan memiliki pengaruh yang baik bagi perkembangan dunia pendidikan. Kegiatan belajar mengajar dapat menjadi lebih menarik dengan memanfaatkan teknologi informasi dan komunikasi. Materi pembelajaran dapat dibuat semenarik mungkin agar dapat menarik minat siswa/mahasiswa, misalnya dengan menggunakan teknik animasi dan memasukkan cuplikan video. Dengan teknologi para guru/dosen dapat menggali tambahan materi pembelajaran dengan menyeleksi materi yang ditemukan di internet, apa saja yang dibutuhkan ataupun yang tidak dibutuhkan untuk menambah wawasan maupun keilmuan. Perkembangan dunia pendidikan dan era teknologi menjadi hal yang prioritas untuk kondisi sekarang ini guna menghasilkan dan mencetak tenaga kerja terampil, unggul dan berkualitas. Revolusi Industri 4.0 merupakan tahap di mana tekonologi informasi digunakan di semua bidang kehidupan, seperti di sektor jasa, dagang, manufaktur, pendidikan, pertahanan dan keamanan, dan bidang lainnya.

Ilmu akuntansi dapat diajarkan mulai dari pendidikan menengah, termasuk di dalamnya sekolah kejuruan, diploma hingga perguruan tinggi yang bertujuan untuk menghasilkan profil lulusan tertentu yang memadukan ilmu akuntansi dan teknologi, terutama teknologi informasi dan komunikasi, sehingga akan dapat dihasilkan outcome atau lulusan yang berkualitas, tangguh, terampil dan paham akan teknologi. Untuk mencapai hal ini, maka kurikulum yang disusun harus memuat materi dan mata pelajaran yang dapat mendukung guna merealisasi tujuan tersebut yaitu menghasilkan lulusan yang mampu menguasai ilmu akuntansi yang berbasis teknologi.

Sekolah Menengah Kejuruan (SMK) jurusan Akuntasi merupakan entitas pendidikan tingkat menengah yang konsisten mempelajari ilmu akuntansi beserta praktiknya. Sekolah Menengah Kejuruan (SMK) jurusan Akuntansi tentunya juga memiliki profil lulusan yang akan dihasilkan, dan profil lulusan ini harus selaras dengan kebutuhan bisnis atau dunia kerja yang selalu berubah dengan sangat cepat, termasuk bisnis berbasis daring yang menuntut lulusan yang menguasai teknologi yang berkembang dengan sangat cepat pula. Respons yang cepat dan tepat dari pihak Sekolah Menengah Kejuruan (SMK) jurusan Akuntansi terhadap berbagai perubahan yang terjadi sangat bermanfaat untuk menyiapkan siswa agar dapat menjadi lulusan yang mempunyai kompetensi sesuai tuntutan zaman.

Tantangan di depan mata yang dihadapi saat ini dalam Revolusi Industri 4.0 bagi dunia pendidikan dan industri adalah pengelolaan proses pembelajaran dan kurikulum pada jurusan Akuntansi bagi lembaga pendidikan dalam memanfaatkan salah satu fasilitas di bidang teknologi informasi. Sejauh mana kesiapan di dunia 
pendidikan dalam mendukung Revolusi Industri 4.0, serta mengubah kurikulum menjadi kurikulum berbasis teknologi informasi.

Perancangan kurikulum Sekolah Menengah Kejuruan (SMK) jurusan Akuntansi hendaknya dilakukan dengan melibatkan para pakar ilmu akuntansi, pengguna lulusan, dan asosiasi profesi. Hal ini bertujuan agar kurikulum dapat berorientasi ke masa depan dan mampu menghadapi perkembangan yang terjadi sebagai konsekuensi dari Revolusi Industri 4.0. Meninjau dan mengevaluasi kurikulum adalah salah satu kegiatan yang akan sering dilakukan oleh Sekolah Menengah Kejuruan (SMK) jurusan Akuntansi agar dapat selalu up to date dengan perkembangan zaman, dan agar muatan teknologi informasi juga dapat tersampaikan ke siswa Sekolah Menengah Kejuruan (SMK) juruan Akuntansi. Dari ulasan ini terdapat permasalahan yang perlu diteliti, yaitu: bagaimana peran Revolusi Industri 4.0 dalam peningkatan mutu pendidikan Sekolah Menengah Kejuruan (SMK) jurusan Akuntansi dalam merespon perkembangan saat ini. Tujuan dalam penelitian ini untuk mendeskripsikan strategi Sekolah Menengah Kejuruan (SMK) Prapanca 2, Surabaya dalam mempersiapkan lulusan Sekolah Menengah Kejuruan (SMK) agar siap menghadapi Revolusi Industri 4.0.

\section{TINJAUAN PUSTAKA}

\section{Revolusi Industri 4.0}

Revolusi Industri 4.0 merupakan proses automatisasi dengan bantuan mesin tanpa keterlibatan tenaga kerja manusia dalam menghasilkan produk yang telah diproduksi. Automatisasi membantu perusahaan dan pelaku usaha/industri untuk mengurangi biaya, waktu, dan tenaga kerja manusia (efisiensi). Smart Factory yang dilakukan oleh pabrik dalam Industri 4.0 merupakan konsep dan proses serta keadaan dalam pengambilan keputusan oleh pihak internal atau eksternal. Informasi data yang dihasilkan dari proses automatisasi dapat dilakukan secara online dan membutuhkan jaringan internet serta mengurangi banyak waktu (on time). Sehingga proses dokumentasi mulai dari pembelian, proses produksi, penjualan hingga pelaporan keuangan dapat terintegrasi dengan internet.

\section{Mutu Pendidikan}

Prinsip dasar dalam pengembangan konsep kurikulum adalah menjadikan peserta didik memiliki mutu yang dapat bersaing di dunia kerja. Kurikulum dikembangkan dalam berbagai program mata pelajaran yang berhubungan erat dengan perkembangan peserta didik yang disesuaikan dengan proses belajar mengajar yang diwujudkan dalam proses pembelajaran menghasilkan kemampuan individu seseorang. Sanjaya (2008) menjelaskan bahwa kurikulum berhubungan erat dengan usaha mengembangkan peserta didik sesuai dengan tujuan yang ingin dicapai.

Peraturan Menteri Pendidikan dan Kebudayaan Nomor 70 Tahun 2013 tentang Kerangka Dasar dan Struktur Kurikulum Sekolah Menengah Kejuruan (SMK)/Madrasah Aliyah Kejuruan (MAK) menyatakan bahwa landasan filosofis, sosiologis, psikopedagogis, dan yuridis yang berfungsi sebagai acuan pengembangan struktur kurikulum pada tingkat nasional dan pengembangan muatan lokal pada tingkat daerah serta pedoman pengembangan kurikulum pada 
Sekolah Menengah Kejuruan (SMK). Sebuah kutipan di dalam media online CNN (2018) menyebutkan bahwa dalam menghadapi Revolusi Industri 4.0 tentunya bukan hal yang mudah. Sederet hal yang perlu dipersiapkan, misalnya saja dengan merubah metode pembelajaran dalam dunia pendidikan yang ada saat ini.

\section{Sekolah Menengah Kejuruan}

Di dalam Undang-Undang Nomor 20 Tahun 2003 tentang Sistem Pendidikan Nasional Bagian Ketiga tentang Pendidikan Menengah pasal 18 disebutkan bahwa pendidikan menengah merupakan lanjutan pendidikan dasar dan pendidikan menengah terdiri atas pendidikan menengah umum dan pendidikan menengah kejuruan.

Pada aturan tersebut pendidikan menengah terdiri atas Sekolah Menengah Atas (SMA), Madrasah Aliyah (MA), Sekolah Menengah Kejuruan (SMK), dan Madrasah Aliyah Kejuruan (MAK), dan bentuk lain yang sederajat. Menurut Jokowi (2018) dalam Setiawan (2018) yang dikutip dalam Kementrian Pendidikan dan Kebudayaan menyatakan bahwa Universitas dan Sekolah Menengah Kejuruan (SMK) mampu mendidik dan mencetak lulusan yang bisa berinovasi dalam menghadapi segala perubahan yang ada. Pendidikan vokasi berbasis kompetensi dapat link and match dengan industri, yaitu pendidikan yang dapat mencetak tenaga kerja dengan keterampilan khusus sesuai kebutuhan pada masing-masing industri.

\section{METODE PENELITIAN}

Penelitian ini menggunakan analisis kualitatif deskriptif (pemaparan) dengan studi kasus pada Sekolah Menengah Kejuruan (SMK) Prapanca 2, Surabaya. Penelitian ini menggunakan pendekatan studi kasus, yang merupakan kajian personal yang unik yang tidak dimilik oleh orang lain atau sekelompok orang lain (Tobing et al., 2016).

Peneliti turun langsung ke lapangan untuk bertemu dan berdialog secara alami. Berdasarkan panduan daftar pertanyaan, peneliti juga melakukan observasi, wawancara secara mendalam. Peneliti juga melakukan pengumpulan data penelitian dengan mengumpulkan berkas di antaranya RPP guru pendamping pelajaran, wali kelas, peserta didik kelas X, XI, dan XII, wakil kepala sekolah bidang kurikulum dan kepala sekolah.

Menurut Daymon dan Holloway (2002) penggunaan metode kualitatif dapat diamati secara seksama dalam aspek tertentu yang berkaitan dengan yang akan diteliti dengan menggunakan latar alamiah, dengan maksud menafsirkan fenomena yang akan terjadi dan dilakukan dengan melibatkan berbagai metode yang ada.

\section{PEMBAHASAN}

Agar para lulusannya memiliki penguasaan teori dan keterampilan praktik yang seimbang untuk dapat bersaing di dunia kerja, terutama guna menghadapi era Revolusi Industri 4.0, maka Kepala Sekolah Menengah Kejuruan (SMK) Prapanca 2, Surabaya terus melakukan upaya mengembangkan metode Teaching Factory (TEFA) yang ada di Sekolah Menengah Kejuruan (SMK) Prapanca 2, 
Surabaya. Teaching Factory (TEFA) merupakan proses belajar berorientasi pada business and production. Suatu proses keahlian atau keterampilan dirancang dan dilaksanakan berdasarkan prosedur dan standar kerja yang sesungguhnya untuk menghasilkan produk yang sesuai dengan tuntutan pasar atau konsumen. Teaching Factory (TEFA) merupakan wadah kegiatan untuk melatih diri dan melakukan praktik berbasis produksi yang dilakukan secara langsung bagi siswa Sekolah Menengah Kejuruan (SMK) Prapanca 2, Surabaya yang berorientasi pada pasar.

Sekolah Menengah Kejuruan (SMK) Prapanca 2, Surabaya yang memiliki kejuruan di bidang Akuntansi, mempunyai harapan agar nantinya setelah para siswa lulus dari Sekolah Menengah Kejuruan (SMK) tersebut bisa langsung bekerja dan mempraktikkan ilmunya dalam bidang akuntansi yang bersinggungan langsung dengan teknologi informasi. Lulusan Sekolah Menengah Kejuruan (SMK) Prapanca 2, Surabaya yang diharapkan adalah lulusan yang telah menguasai konsep akuntansi dan mampu menjalankan program aplikasi akuntansi, seperti antara lain: Microsoft Accsess, MYOB, Accurate.

Kualitas guru merupakan prioritas utama yang sangat diperhatikan dalam proses pembelajaran pada Sekolah Menengah Kejuruan (SMK) Prapanca 2 Surabaya. Dinas Pendidikan (Diknas) Kota Surabaya memberikan dukungan dalam meningkatkan kompetensi guru untuk terus diupayakan agar dapat menghasilkan guru yang unggul dan terampil di bidang yang dikuasai, khususnya pendidikan akuntansi. Peningkatan kualitas guru dilakukan dengan cara memberikan kesempatan mengikuti kegiatan bimbingan secara teknis (bimtek) dari daerah ataupun pusat. Upaya peningkatan kompetensi guru dilakukan tiap tahun bagi guru Sekolah Menengah Kejuruan (SMK) Prapanca 2, Surabaya. Kepala Sekolah Menengah Kejuruan (SMK) Prapanca 2, Surabaya juga memberikan motivasi agar para guru dapat aktif dalam komunitas guru mata pelajaran (MGMP) guna meningkatkan ilmu dan wawasan yang dimiliki oleh para guru di setiap bidang ilmu.

Upaya yang dilakukan dalam memenuhi fasilitas sarana dan prasarana (sarpras) pada ruang laboratorium praktikum disesuaikan dengan materi Uji Kompetensi yang diharapkan dapat meluluskan anak didik Sekolah Menengah Kejuruan (SMK) Prapanca 2, Surabaya yang mampu mengoperasionalkan komputer baik secara offline (desktop) maupun secara online di dalam dunia kerja. Fasilitas sarana dan prasarana yang diperlukan pada ruang laboratorium praktikum pada jurusan Akuntansi, telah dikelola dengan manajemen aset yang baik, di mana untuk setiap peralatan yang ada dan media penunjang alat praktikum dilakukan inventarisasi dan pencatatan, serta dikontrol kelayakannya untuk dipergunakan praktikum secara berkala.

Peneliti juga melihat bahwa Kepala Sekolah Menengah Kejuruan (SMK) Prapanca 2, Surabaya sebagai pemimpin sudah menjalankan peranannya dengan sangat baik dan sukses dalam meningkatkan mutu lulusan dan manajemen pendidikan. Kepala Sekolah Menengah Kejuruan (SMK) Prapanca 2, Surabaya juga memiliki kemampuan leadership yang bagus dan dapat menjadi contoh yang baik kepada semua personil yang ada di Sekolah Menengah Kejuruan (SMK) Prapanca 2, Surabaya. Kesuksesan dalam manajemen pendidikan tergambarkan dengan adanya pengelolaan administrasi surat-menyurat yang rapi 
di bagian administrasi umum, keuangan, perpustakaan yang berjalan dengan baik serta pengelolaan kurikulum yang selalu diperbahurui secara sistematis disesuiakan dengan kebutuhan dunia kerja, terutama di era Revolusi Industri 4.0. Kegiatan ini dilakukan dengan bekerjasama sebagai tim kerja yang profesional, kreatif, dan inovatif.

\section{SIMPULAN}

Hasil penelitian yang dilakukan menunjukkan bahwa Sekolah Menengah Kejuruan (SMK) Prapanca 2, Surabaya telah siap untuk bersaing untuk menghasilkan lulusan yang sesuai dengan kompetensi yang diinginkan oleh dunia kerja di era Revolusi Industri 4.0. Strategi yang dilakukan oleh Sekolah Menengah Kejuruan (SMK) Prapanca 2, Surabaya sudah sesuai dengan kebutuhan Dunia Usaha (DU)/Dunia Industri (DI). Beberapa strategi yang digunakan Sekolah Menengah Kejuruan (SMK) Prapanca 2, Surabaya dalam menyelaraskan pendidikan dengan tuntutan era Revolusi Industri 4.0 antara lain:

a. Link and Match dengan kebutuhan DU/DI terkait, pengembangan kurikulum dan pemenuhan sarana serta prasarana.

b. Peningkatan kompetensi guru difokuskan dengan kebutuhan pada era Revolusi Industri 4.0.

c. Peran Kepala Sekolah Menengah Kejuruan (SMK) Prapanca 2, Surabaya yang berwawasan luas, terbuka, disiplin, tegas, memiliki komitmen yang tinggi terhadap mutu pendidikan, kreatif dan berinovasi, sehingga dapat menjadi suri teladan bagi para kolega guru maupun tenaga kependidikan.

\section{SARAN}

Hasil penelitian ini diharapkan akan memberikan implikasi positif terhadap strategi sekolah dalam meningkatkan mutu pendidikan yang melibatkan kepala sekolah, guru, tenaga kependidikan, siswa, dan masyarakat pada umumnya, agar memiliki pola pikir yang sama untuk mendapatkan hasil yang berkualitas.

\section{DAFTAR KEPUSTAKAAN}

CNN, 2018, Metode Pendidikan Baru Menghadapi Revolusi Industri 4.0, https://www.cnnindonesia.com/gaya-hidup/20180904182901-284-327637/me tode-pendidikan-baru-menghadapi-revolusi-industri-40, diakses tanggal 21 Januari 2019, pukul 10.00 WIB.

Daymon, Christine Daymon and Immy Holloway, 2002, Metode-Metode Riset Kualitatif dalam Public Relations \& Marketing Communications, Bentang, Yogyakarta.

Peraturan Menteri Pendidikan dan Kebudayaan Nomor 70 Tahun 2013 tentang Kerangka Dasar dan Struktur Kurikulum Sekolah Menengah Kejuruan (SMK)/Madrasah Aliyah Kejuruan.

Sanjaya, Wina, 2008, Kurikulum dan Pembelajaran: Teori dan Praktik Pengembangan Kurikulum Tingkat Satuan Pendidikan (KTSP), Prenadamedia. 
Setiawan, Rizky, 2018, Revolusi Industri 4.0 dari Mata Pendidikan Vokasi, Bagikhttps://psmk.kemdikbud.go.id/konten/3983/revolusi-industri-40-dari-ma ta-pendidikan-vokasian Twit! Google+, disampaikan 9 Oktober 2018, pukul 13.50 WIB, diakses tanggal 20 Januari 2019, pukul 21.00 WIB.

Sugiyono, 2013, Metode Penelitian Pendidikan (Pendekatan Kuantitatif, Kualitatif, dan $R \& D)$, Penerbit Alfabeta, Bandung.

Tobing, David Hizkia, Naomi Vembriati, Yohanes Kartika Herdiyanto, Ni Made Ari Wilani, Dewi Puri Astiti, Ni Made Swasti Wulanyani, I Made Rustika, Putu Nugrahaeni Widiasavitri, Komang Rahayu Indrawati, Putu Wulan Budisetyani, Luh Kadek Pande Ary Susilawati, Supriyadi, Luh Made Karisma Sukmayati Suarya, Adijanti Marheni, Made Diah Lestari, 2016, Bahan Ajar Metode Penelitian Kualitatif, Program Studi Psikologi, Fakultas Kedokteran, Universitas Udayana.

Triyono, Moch. Bruri, 2017, Tantangan Revolusi Industri Ke-4 Bagi Pendidik Vokasi, Seminar Nasional Vokasi dan Teknologi (SEMNASVOKTEK), Denpasar-Bali, ISSN Cetak: hal. 2541-2361/ISSN Online: hal. 2541-3058.

Undang-Undang Nomor 20 Tahun 2003 tentang Sistem Pendidikan Nasional.

Wahyuni, Fitri, 2015, Kurikulum dari Masa ke Masa (Telaah atas Pentahapan Kurikulum Pendidikan di Indonesia, Jurnal Al-Adabiya: Jurnal Kebudayaan dan Keagamaan, Vol. 10, No. 2, hal. 231-242.

Widodo, Joko, 2018, Kecepatan Kunci Utama Memenangkan Kompetisi di Era Revolusi 4.0, Siaran Pers. No:191/SP/HM/BKKP/X/2018, Biro Kerjasama dan Komunikasi Publik, Kemenristekdikti.

Winarso, Widodo, 2015, Dasar Pengembangan Kurikulum Sekolah, Jakarta.

Yahya, Muhammad, 2018, Era Industri 4.0: Tantangan dan Peluang Perkembangan Pendidikan Kejuruan Indonesia, Disampaikan pada Sidang Terbuka Luar Biasa Senat Universitas Negeri Makasar, Pidato Pengukuhan Penerimaan Jabatan Profesor Tetap dalam Bidang Ilmu Pendidikan Kejuruan Fakultas Teknik Universitas Negeri Makasar. 